\title{
Value creation in projects: Towards a narrative perspective
}

\section{Abstract}

It is contended that value is a social construct, and that the processes of social construction are rooted in language. On this basis we argue that value creation is a process which lends itself to interpretation from a narrative perspective. Previous attempts at value creation have been promoted under the label of 'value management'. There are two approaches which are identifiable in the literature. The first is based on the traditional narrative of value engineering (aka Hard VM) and is primarily directed towards cost reduction. The second more recent variant is labelled 'soft' value management (Soft VM) and is primarily directed towards the achievement of a shared understanding of the value criteria relating to an individual project. The two approaches are critiqued in terms of their underlying assumptions and it is suggested that they are best understood as different forms of narrative. The emerging literature on value creation is similarly critiqued in accordance with the adopted narrative perspective. The distinction is made between formalised narratives of value on the level of the organisations involved in the project coalition and the anecdotal stories which individuals use to make sense of their own lived experiences. Emphasis is given to the ways in which different narratives interact, and to the way in which they remain contestable over time. Particular attention is given to the confluence between storytelling and identity work.

Key words: Narrative, Identity work, Project management, Value creation, Value management

\section{Introduction}

There has in recent years been considerable debate about judging project success on the basis of value (APM, 2018; Chang et al., 2013; ICE, 2017; Laursen and Svejvig, 2016; Lepak et al., 2007). The recent emphasis on 'value' has in part emerged from the longstanding debate about how to assess project 
success. The debate has resulted in a significant shift in emphasis within the project community from 'product creation' to 'value creation' (Winter and Szczepanek, 2008). This shift is indicative of a broader quest to position project management evermore strategically. Martinsuo and Killen (2014) emphasise the importance of identifying and assessing strategic, non-commercial value in project portfolios. In seeking a route forward Laursen and Svejvig's (2016) point towards the established subdiscipline of value management as a promising source of ideas for the project community. They especially highlight the contribution of Male et al. (2007) as having potential in offering an integrated approach which embraces value, benefits and costs. However, they notably neglect the broader theoretical debates within value management and the associated 'paradigm wars' within the fields of operational research (OR) (cf. Ackoff, 1987; Keys, 1984; Rosenhead and Mingers, 2001) and systems thinking (cf. Checkland, 1981; Mingers, 1980). It is contended that these debates have significant implications for the way 'value creation' is conceptualised and enacted within context of projects. It will further be argued that current approaches to value creation tend to reify value and hence treat it as objective commodity which is subject to rational manipulation. In this respect the literature risks replicating previous debates about project success (Ika 2009; Jugdev and Müller, 2005; Pinto and Slevin, 1988).

\subsection{Value creation from a narrative perspective}

The paper is conceptual in nature. It derives its theoretical basis from the 'narrative turn' in organisation studies (Rhodes and Brown, 2005; Vaara et al., 2016). Narrative approaches notably remain on the margins of the project management research community, despite a number of significant contributions (e.g. Amtoft, 1994; Boddy and Paton, 2004; Gil, 2010; Musca et al., 2014). Boddy and Paton (2004) contend that competing narratives are inevitable in major projects as a consequence of the conflicting subjective interpretations of different interest groups. They further argue that there is a need for project managers to create structures within which these competing narratives might be managed. Havermans et al. (2015) are much stronger in terms of their reliance on 
narrative theory, and notably place language at the very centre of project organising. They further draw convincingly from narrative sources such as Boje et al. (2004) to argue that language is constitutive of organisational reality rather than merely representative. It is not necessary to accept this view in its entirety to contend that value is a social construct, and that the processes of social construction are rooted in language. It is on this basis that we argue that value creation is a process which lends itself to interpretation from a narrative perspective.

The research problem the paper seeks to address is the longstanding lack of progress in respect of how through-life value creation should be conceptualised and enacted in the context of projects. It is contended that the recurring failure of attempts to reify value requires a radically different approach from those which have prevailed to date. The adopted style of the current paper is deliberately provocative in an attempt to challenge current institutionalised ways of thinking. The arguments are primarily aimed at the project management research community, but lessons are also offered to practitioners not least in terms of how they might better position themselves within current debates.

\subsection{Value as a social construct}

The essential proposition is that 'project value' is best understood as a social construct which is continuously contested amongst project participants. Kreiner (2014) has similarly argued that project success is a matter of negotiated agreement as much as objective achievement. The difficulty with project success is that any definitive judgement depends upon a negotiated reconciliation of differing perspectives among project stakeholders, and any such reconciliation is unlikely to remain stable over time. The same argument also prevails in the case of project value. In this paper we adopt the position that value is an entirely abstract concept which is continuously shaped and contested through narrative. This is especially true in the case of the non-commercial strategic value to which Martinuo and Killen (2014) allude. To be clear, the adopted position is that there is no underlying 'reality' of strategic value which exists independently of narrative. We would further contend that the narrative of value creation is popular because it serves to enhance the status of project management as a 
discipline, and that of the individual project managers who seek to justify their actions in these terms. Hence we ultimately interpret the continued advocacy of value creation as 'identity work'. Such an interpretation leads to a research agenda for value creation which stands in sharp contrast to those currently advocated.

The adopted perspective is in part a response to an increasing appetite for alternative theoretical perspectives within the international research community relating to the 'management of projects' (cf. Cicmil and Hodgson, 2006; Smyth and Morris, 2007; Söderlund, 2004). We would recognise however that the majority of popular project management textbooks and bodies of knowledge continue to be based on an implicit realist ontology (Gauthier and Ika, 2012). Hence the argument that value is socially constructed through narrative may seem strangely 'unscientific' to many within the project management research community. For this reason we go to some length to emphasise the limitations of currently favoured approaches to value creation prior to advocating the case in support of a narrative approach.

\subsection{Structure}

The paper is structured as follows. First, attention is given to the concept of through-life value creation as currently advocated in the project management literature. Next, consideration is given to the 'paradigm wars' which characterise the established sub-discipline of value management. Despite prolonged interest in value management amongst project scholars, there has to date been limited engagement with such theoretical debates within the mainstream project literature. However, rather than position competing paradigms of value management in opposition it will be argued that they comprise complementary 'ways of seeing'. In this sense the argument broadly concurs with previous pleas for pluralism in project management research (Söderlund, 2011; Stingl and Geraldi, 2017). However, the discussion extends beyond schools of thought vis-à-vis research to question the extent to which such paradigms can ever be enacted in practice. Thereafter, the theoretical basis of value creation as currently advocated within the project management literature is reviewed and critiqued. 
It is considered especially important to challenge the recurring tendency in the literature to reify value and hence render it manageable by rationalistic methods. Attention is given more broadly to the theoretical elusiveness of value creation as currently conceptualised. This is seen to comprise a significant barrier to the development of a theoretically-informed research agenda. The discussion encompasses creative projects in addition to the more usual focus on capital projects. Particular attention is given to 'value management as a methodological style' as notably endorsed by Laursen and Svejvig (2016). The critique is further extended to those approaches which rest on the reification of 'client value systems'. The paper is concluded by the articulation of the advocated narrative perspective on value creation with appropriate recommendations for further research.

\section{Through-life value creation}

\subsection{Evolving models of project management}

Winter et al. (2006) identify three dominant strands of thinking in project management. The first is the 'hard' systems model which is held to be predominantly concerned with planning and control. The second focuses on forms of project organisation and the third adopts a broader view of projects which is primarily influenced by the seminal work of Peter Morris (1994). Winter et al. (2006) highlight the latter strand's emphasis on the front-end of projects and the recognition of the need to manage the exogenous factors which lie beyond the way in which project management is traditionally defined. Morris (2004) notably makes specific reference to 'value management' as an area of interest for those interested in the front-end of projects. Subsequent authors such as Ahola et al. (2008) and Winter et al. (2006) prefer to emphasise the terminology of 'value creation'. Winter and Szczepanek (2008) are particularly cogent in positioning projects and programmes as value creation processes with a corresponding need for a more strategic focus. Martinsuo and Killen (2014) go further in seeing strategic value as comprising ecological, social, health and safety, societal influence learning and knowledge development and longer term business value. Artto et al. (2016) further argue in support 
of the need to manage projects in terms of through-life value creation. There is therefore a strong emerging consensus in favour of the need to move away from the traditional 'hard systems' focus on product creation to a broader perspective which embraces through-life value creation. However, there remains little agreement on how the value creation perspective might meaningfully be operationalised in practice.

\subsection{Project value creation: taking stock of current thinking}

Laursen and Svejvig (2016) offer a useful review paper which seeks to 'take stock' of current thinking on project value creation. There was seemingly a time when project managers did not worry about such things. The starting point for the discussion is provided by Atkinson (1999), who argues the need to judge project success in terms other than time, cost and quality, i.e. to move beyond the constraints of the so-called 'iron triangle'. The essence of Atkinson's argument is that the way in which project management is defined has shaped the way in which success is assessed. This is a telling observation, not least in its recognition of the way in which practice is irrevocably shaped by theory. More recent definitions of project management such as that advocated by Cleland and Ireland (2002) notably emphasise the importance of working with stakeholders to define needs and expectations (Jugdev and Müller, 2005). Hence project managers in the modern era accept that liaising with stakeholders becomes an important part of their role (Chang et al., 2013). Once again, it is the evolving theory of project management which creates new expectations of what practising project managers are supposed to do and the issues which they are expected to address. Thinking has therefore shifted decisively towards the strategic value created from projects, not only for the sponsoring organisation(s), but also for a much broader range of stakeholders. Value can otherwise be construed as 'benefits realisation' which is especially notable for its through-life perspective (Serra and Kunc, 2015). The point is that changing conceptualisations of project management create new narratives for practitioners highlighting the need to give attention to often intangible notions of 'value' and 'benefit'. 


\subsection{Avoiding theoretical cul-de-sacs}

Notwithstanding the strong rhetorical arguments in favour of project value creation the discussion lacks any strong unifying theoretical dimension. It also lacks specific guidance on how practitioners should respond to the espoused agenda in favour of value creation. An important strand of work often overlooked by the mainstream project management community relates to previous attempts to address value creation within the specific sub-discipline of value management (Green, 1994b; Male et al. 2007; Thomson et al 2003). It is important to emphasise there are no panaceas to be found within the literature on value management. Our motivation in bringing these debates to the attention of the projects community is in no small way to prevent others from pursuing similar theoretical cul-de-sacs. But these previous debates nevertheless have significant implications for the way 'value creation' is conceptualised and enacted within the context of projects. The limitations of the advocated approaches are further important in pointing the way towards a narrative approach.

\section{Competing paradigms in value management}

Prior to addressing the issue of competing paradigms within the sub-discipline of value management, it is important to emphasise that the relevant literature at large tends to be strong on rhetoric and rather less strong in terms of underpinning theory. The review which follows is hence focused very specifically on the more theoretical contributions. The domain is also plagued by issues of terminology. The initial preferred descriptor was 'value engineering'. The subsequent shift to 'value management' was notably inspired by the same logic that prevails within the projects community vis-à-vis the shift from product creation to value creation. Whether or not this shift has been achieved in practice is a moot point, and is an issue of no small importance. But the immediate aim is to provide a stronger theoretical foundation for current debates about value creation in projects. 
It is important to be clear from the outset that the paradigms under discussion are advocated as 'paradigms of practice'. As such they differ from Söderlund's (2011) literature-based analysis of project management schools of thought. The latter are characterised by the research questions that they pose, the type of theorising in which they engage, and the methodological approaches adopted. However, there is little comment on how practitioners might align with the various schools of thought, and the extent to which the various theories play a performative role in shaping practice. The same is also true of the schools of thought presented by Stingl and Geraldi (2017) in their review of behavioural decision making in projects. As valuable as these contributions are, they are not primarily concerned with 'paradigms of practice' in the sense which is advocated here.

\subsection{Hard VM}

The idea of a paradigm crisis in value management was initiated by Green (1994a), who directed his critique at the original 'paradigm of practice' as epitomised by sources such as Dell'Isola (1982). The argument presented by such sources emphasises the need for a systematic approach, thereby aligning with 'hard systems thinking' as defined by Checkland (1981). Such approaches are characterised as 'Hard VM' in that they are primarily concerned with the achievement of functional performance at minimum cost (Green, 1994b). The guiding concern lies with the most effective way of locating the optimal solution as defined in accordance with a predefined set of criteria. The 'objective function' in some cases may relate to simplistic notions of cost reduction, and in others may involve more complex multi-criteria definitions of value. Both cases are characterised by a recurring tendency to abolish future uncertainty, or at least to collapse it into a single numerical value such as net present value (NPV) whereby future income streams are discounted to the present.

The implicit epistemology of objectivism is notably shared with the optimisation paradigm of operational research (OR). Similar arguments have been offered in respect of the traditional 'hard systems' model of project management, which was likewise seen to be of limited applicability to the front end of projects (Winter et al., 2006; Yeo, 1993). The rhetoric of Hard VM also aligns strongly with 
the optimisation school of project management as articulated by Söderlund (2011). Indeed, the optimisation paradigm is largely synonymous with the traditional OR-type interpretation of project management whereby 'research' is mobilised in the direct (and narrow) cause of identifying hypothetical optimal solutions. The key defining characteristic of Hard VM is the implicit objectivist assumption that the solution space exists 'out there' as part of an external reality.

The rhetoric of optimisation notably remains persuasive amongst many project management practitioners, not least because of the way in which it reflects and reinforces a historical cultural bias towards technical rationality. This remains true despite the recognised limitations of 'bounded rationality'. Simon $(1955,1956)$ famously challenged assumptions of global rationality on the basis of the impossibility of perfect information and the limited processing capacity of the human brain. Notions of mathematical optimisation were hence replaced by the idea of 'satisficing', i.e. searching through the available alternatives until an acceptability threshold is met as measured against a range of criteria. This translates directly to the domain of value creation where uncertainty about the future discounts any idea of value optimisation. But to advocate the cause of 'finding solutions which are good enough' undoubtedly lacks the same rhetorical appeal. Both approaches however are characterised by an underlying reliance on logical positivism. The point is that any notion of value maximisation beyond the 'life worlds' of individual decision-makers is discredited even if a commitment to logical positivism remains intact.

In light of the above, it is wise to be cautious in terms of what we construe as a shift in thinking. The shift from evaluating project success on the basis of the 'iron triangle' to judging it on the basis of through-life value creation does not in itself constitute a 'paradigm shift'. It does however represent an important attempt to extend the 'life worlds' within which decisions are made. Those whose life worlds are dominated by economics understandably focus on criteria such as NPV, but even here notions of optimisation flounder on the basis of future uncertainly. Furthermore, diverse communities of project stakeholders are unlikely to be comfortable to see their expectations reduced to a single 
measure of NPV. Hence the arguments in support of an increased focus on 'strategic value' (cf. Martinsuo and Killen, 2014).

\subsection{Soft VM}

Winter et al. (2006) are notably dismissive of the body of ideas which they label 'value management' on the basis that they are 'historically and intellectually' aligned with the product creation perspective. This is undoubtedly true of the above described characterisation of Hard VM. However, Winter et al. give little emphasis to the established alternative conceptualisation of 'soft' value management (Soft VM) which tentatively started to emerge from the mid-1990s (cf. Green, 1994b). In its original version Soft VM followed the decision conferencing approach developed by Phillips (1984). Of central importance was the use of a multi-attribute decision model as the basis for negotiating a 'shared social reality'. In sharp contrast with the tradition of Hard VM, there is no pretence of modelling a supposed objective external reality. The explicit espoused epistemological position is that of social constructivism. Green (1994b) labelled his approach 'SMART value management' and the advocated techniques were subsequently promoted by sources such as HM Treasury (1996) and ICE (1996). However, such sources notably remained entirely uninterested in underlying issues of epistemology. As an aside, financial investment appraisal models can similarly be viewed in terms of establishing a shared inter-subjective understanding of the likely benefits of making a particular investment. Investment models would hence be developed until such point as they were considered 'requisite' for the purposes of making the decision. Such an interpretation would be entirely consistent with the limitations of bounded rationality.

Green (1999) subsequently developed the articulation of Soft VM in alignment with the broader principles of 'Soft operational research' (Soft OR) as advocated by Rosenhead and Mingers (2001). The original decision-conferencing approach hence became just one option among several. Other identified potential approaches included 'strategic choice' (Friend and Hickling, 1987) and 'soft systems methodology' (Checkland, 1981, 2001). Soft VM hence morphed into a problem-structuring 
methodology through which project stakeholders could negotiate a shared understanding of project definition. Thiry's (2001) interpretation of value management as a means of sensemaking can be seen to share a similar constructivist epistemology. In sharp contrast to Hard VM - and the so-called 'hard' systems approach generally - such approaches are primarily focused on building and maintaining a stable political constituency within which the project is delivered. Unclear objectives and resultant mission creep have long-since been recognised of one of the biggest causes of project failure (Morris, 2013; Winch, 2013). The focus on 'ambiguities and conflicts' is reminiscent of Söderlund's (2011) behavioural school of project management. Certainly it is no longer contentious to claim that the achievement of project success depends on managing the social and political aspects which surround projects (cf. Boddy and Patton, 2004; Zwikael and Smyrk, 2012), and it is this agenda at which Soft VM is directed. The aim is to enact a collective process of learning whereby participants converge on an emergent understanding (cf. Thiry, 2002). Hence the emphasis on participation as a key component. It is worth emphasising that Soft VM is inherently a social process, in contrast with the dominant instrumentalism of Hard VM.

The unifying feature shared by the two competing paradigms is a reliance on episodic workshops. In this sense, value management is conceptualised as a designed intervention in the cause of value creation. The Hard VM storyline emphasises the role of technical experts in achieving a specified function at minimum cost. In contrast, the narrative of Soft VM emphasises the need to engage with identified stakeholders with a view to understanding more strategic interpretations of value. In both cases, there is an assumption that decision support can meaningfully be enacted within the constraints of a workshop. The important point is that what happens in the workshop is inevitably shaped by the way in which 'value' is conceptualised. The issue here is that of performativity, i.e. the extent to which material practices are shaped by the narratives which are mobilised.

\section{Beyond the paradigm wars}




\subsection{Criticisms of Soft VM}

Soft VM of course has not been without its critics, and there are recurring doubts regarding the extent to which it has been adopted in practice (Ellis et al., 2005). Crawford et al. (2003) make a similar point about 'soft' methodologies more generally. Gillier et al. (2015) in turn contend that Soft VM is of little use if the 'beneficiaries' of the project are unknown. This is undoubtedly an issue of some importance, with significant implications for the way in which 'value creation' might be conceptualised. Yet the beneficiaries of projects are rarely fully identifiable at the point at which the facility or product is designed. In the case of capital projects, many long-term beneficiaries may not even be born when the facility becomes operational. And even in those (rare) cases when all beneficiaries can be identified from the outset, their preferences will undoubtedly change over time - not least because their expectations will change as they learn. A more pertinent criticism is that Soft VM inevitably serves to reinforce the vested interests of key stakeholders - to the detriment of others. Indeed, the advocates of a critical perspective would argue that only those stakeholders whose views are broadly compatible with those of the dominant interest group are likely to be invited to participate. Even with those stakeholders who are represented, the process may be manipulated in support of vested interests. Such criticisms resonate with those made by researchers from within the 'Making Projects Critical' perspective (see Hodgson and Cicmil, 2006).

Perhaps the most pointed criticism of Soft VM is that it tends to de-emphasise the importance of facts and logic. There is clearly a danger in prioritising the achievement of an 'easy' consensus in isolation of any engagement with the evidence. It would be difficult to defend such an approach on the basis of procedural rationality. Hard VM and Soft VM are therefore both subject to criticism, although it can be argued that both storylines have a degree of validity in different circumstances (Green and Liu, 2007). But it would be unrealistic to expect theoretical purity amongst practitioners who tend to be entirely uninterested in issues of epistemology. Many published codifications of value management are stubbornly resistant to paradigmatic classification, not least because they are themselves 
negotiated outcomes of a politicised process. Even more pertinently, there are doubts regarding what it means for a methodology to be 'adopted' given that epistemological assumptions are not directly accessible empirically (Green and Liu, 2007). It is also frankly quite arrogant to assign assumptions to practitioners on the basis of their supposed adherence to different paradigms - as if practitioners were 'cultural dupes' who are incapable of actively constructing their own social worlds (cf. Garfinkel, 1967). As will subsequently be argued, practitioners are often highly adept at mobilising externally-produced scripts to serve their own ends.

\subsection{Complementary ways of seeing}

Of further note is that the paradigm wars within value management were relatively short-lived. Indeed, the equivalent hostilities within operational research (OR) ultimately resulted in an informal ceasefire (Mingers and Gill, 1997). Positivists came to accept that there are aspects of the social world which are not subject to quantification, and interpretivists similarly came to accept that there are aspects of the social world which lie beyond individual interpretations. Notions of paradigmatic incommensurability gradually give way to an acceptance that different paradigms provide different ways of seeing (Mingers, 2004). In other words, it became accepted that the supposedly irreconcilable paradigms accentuate different aspects of reality. An idealistic pluralist approach to value creation would seek to draw insights from both Hard VM and Soft VM, and perhaps on occasion even from a critical perspective which focuses on the exposure of vested interests. Such a view in part echoes Söderlund's (2011) plea for pluralism in respect of the competing schools of project management. However, as previously observed, Söderlund's typology gives little attention to the role the various schools play in shaping enacted practice.

It must further be acknowledged that so-called 'soft' methodologies have long since been advocated within the project management research community. This is especially true of Checkland's soft systems methodology (SSM) as an aid to project definition (Crawford et al., 2003; Yeo, 1993). However, despite this sustained interest, issues of paradigmatic commensurability remain relatively 
unexplored. Indeed, there is a recurring confusion in terms of what the prefixes 'hard' and soft' actually mean. For example, Crawford et al. (2003) distinguish between hard and soft projects as if they are in some sense substantially different. Winter et al. (2006) argue the case for more 'holistic' thinking whereby projects are seen to incorporate both 'hard' and 'soft' aspects. This again seems to imply that the distinction is lodged in the real world, rather than the way in which we chose to think about the real world. The distinction is subtle, but nevertheless important.

\subsection{Pluralism constrained}

Although the idea of pluralism is attractive, it is necessary to caution against a view which suggests that practitioners are able to choose between alternative paradigms as if they were products on a supermarket shelf. The reality is that practitioners are invariably pre-conditioned to privilege some ways of seeing over others. Yeo (1993) argues that professional project managers tend to accept the 'hard systems' paradigm without question. Indeed, it could be argued that managers become conditioned into particular ways of representation by the social structures within which they operate. Socialisation into institutionalised narratives is of course part of what it means to be accepted as a professional (Paauwe and Boselie, 2006). This applies equally to project management and to countless other professions. Of no small importance is the requirement to adopt the requisite terminology. Hence the debate shifts away from the supposed underlying epistemological assumptions of different paradigms towards the narratives which are used. Perhaps the paradigm wars are best left in the ivory towers from where they originated. Amongst practitioners, persuasiveness of argument will forever take precedence over epistemological consistency; and persuasiveness too often depends upon alignment with existing institutionalised narrative.

\section{Value creation: in search of a theory}


The preceding discussion provides the essential theoretical platform from which to critique the current trajectory of arguments in support of value creation. Particular attention is given to the approaches which are considered by researchers from within the projects community to have the most potential. It is important to emphasise that critique is not only important for its own sake, but also as the medium through which knowledge progresses.

\subsection{The reification of value}

As already noted, the recent emphasis on value creation has been mooted as an alternative to the supposed traditional focus on product creation. Although this is not quite presented in terms of a 'paradigm shift' it does nevertheless comprise a similar plea in support of a fundamental change in thinking. Winter et al. (2006) describe how the shift to value creation was a strong theme to emerge from their consultations with practitioners. They further argue for the need to recognise different forms of value, and point towards the need for new models of value creation which extend beyond project completion. This agenda is in a sense legitimate in that it represents the concerns of the practitioners with whom they consulted, but it is also notable for its gentle tendency towards the reification of value. In other words, it is indicative of a prolonged project to translate the abstract construct of value into something which is real, and hence subject to managerial manipulation. Echoes here of Zen and the Art of Motorcycle Maintenance (Pirsig, 1974).

The same tendency towards reification is evident in Laursen and Svejvig's (2016) summary of the literature on 'project value creation'. They commence by describing value creation as a complex and multifaceted concept which leads to much confusion. The implied research challenge is to remove the causes of confusion. They further draw from Lepak et al. (2007) for an explanation of why such confusion occurs. Reasons offered relate to the multidisciplinary nature of management, a blurring between issues of content and process, and a perceived disconnect between value creation and value capture. This discussion results in a suggested distinction between 'perceived use value', as subjectively assessed by the user, and 'exchange value', as determined by the marketplace. Such 
distinctions are hardly new and in the case of construction projects have been debated since at least the mid-1960s (Stone, 1966). Such difficulties of definition are of course characteristic of any attempt to reify an abstract concept.

\subsection{Theoretical elusiveness}

The current literature on value creation is further characterised by a recurring elusiveness in terms of its underlying theory. Laursen and Svejvig (2016) notably refer to value management as an approach which seeks 'to optimise both benefits and costs in projects'. The focus on optimisation is telling, and is indicative of a lack of sensitivity to the paradigm wars described above. They further allude to 'value creation' as a research area which pulls together the associated fields of benefits management, strategic management and value management. The research agenda offered is undoubtedly ambitious in scope, but ultimately lacks any clear underlying theoretical framework. The literature is further characterised by a recurring aspiration for a more precise definition of relevant concepts, as if such concepts are in some way representative of an external, objective reality (cf. Tsoukas, 1994). The overall tone is that definitions of value need to become ever more inclusive of an increasing variety of issues to be considered over an ever-extending timeframe. Even if the advocated world-view is accepted, there is a notable absence of any recognition of the constraints of bounded rationality. In advocating the need for a more 'integrated view' it is notable how Laursen and Svejvig (2016) exclude any explicit consideration of the way in which judgements about value are invariably made in conditions of uncertainty.

Of further interest is the paper by Thysssen et al. (2010) which advocates a workshop approach to value creation in accordance with the tradition of value management. The argument follows Thomson et al. (2003) in blurring between 'client value' and 'values' in the sense of the beliefs held by individuals. This tendency towards blurring is reflective of a recurring confusion regarding the unit of analysis which should be adopted for the purposes of value creation. Thyssen et al. (2010) notably adopt a pluralistic model of the client comprising a range of stakeholders who are seen to have 
different and often conflicting values and needs. Even more pertinent is the explicit recognition that 'values and needs' may well be subject to change over time - even extending beyond the point of what is usually understood as 'project completion'. The adopted focus on consensus building is indicative of an underlying political metaphor, thereby reflecting the key tenets of Soft VM. The recognition that values may change over time is also indicative of a learning metaphor which is again indicative of Soft VM. However, there remains an absence of any explicit theoretical framework. The following quote is especially evocative:

“...the case study shows that speaking of value is a tricky thing and a more rigorous use of quality function deployment may help to translate the client values into a language understandable to building professionals." (Thyssen et al., 2010, p. 28)

The explicit recognition of 'speaking of value' is suggestive of a sensitivity to the ways in which project stakeholders speak of value, or phrased rather differently, the narratives that they mobilise. In contrast, the plea for a more rigorous use of quality function deployment would seem to revert to the instrumentalist thinking of Hard VM. The emphasis on the 'translation' of client values into a different language seems to hint at an assumed relative fixity, and yet Thyssen et al. (2010, p. 29) are equally clear that 'value is not something than can be made explicit once and for all'. In short, the theoretical assumptions behind the advocated approach are at best illusive. This is a recurring theme of much of the literature on value creation.

\subsection{Creative projects}

Gillier et al. (2015) refreshingly move beyond the context of capital projects to address the applicability of value management from the perspective of creative projects. Their analysis offers a stronger degree of theoretical positioning, and a useful critique of the competing paradigms of Hard VM and Soft VM. They conclude that both approaches assume a 'stable design regime perspective'. This is to a degree a valid criticism. The advocates of Soft VM explicitly privilege 'problem-structuring' over 'problem-solving'. However, the decision to enact Soft VM in the construction sector (for 
example) often flows from a pre-existing assumption that there is a need for a capital project. This remains broadly true even if the enactment of Soft VM precedes the appointment of the design team (Green, 1999). Hard VM and Soft VM can hence both be seen to be essentially regularity in nature with associated assumptions of contextual stability.

Gillier et al. (2014) further argue that traditional project control procedures tend to inhibit learning, innovation and creativity. The implicit organisational metaphor here would seem to be that of the physic prison, with an overriding narrative on how to break free from the constraining influence of existing structures (cf. Morgan, 2006). The advocates of Soft VM would certainly agree with the recommendation that creative projects should not be evaluated (solely) on the basis of 'conventional quantitative criteria' such as discounted cash flow and NPV. Indeed, this is perhaps the central argument upon which the justification of Soft VM depends. Nevertheless, there is merit in Gillier et al.'s (2014) emphasis on the dangers of perennially seeking to reduce uncertainty and ambiguity. Soft OR would share the aspiration of 'playing with uncertainty' so that participants can learn from each other. Checkland (2001) is especially explicit in emphasising the importance of not striving for a unified view. Soft VM is however shaped by an expectation that decisions have to be made, and that such decisions in turn have direct material consequences. Such assumptions are arguably directly shaped by the materiality of capital projects, with direct consequences for the conceptualisation of value creation. Nevertheless, there is undoubtedly a bias towards action across the project management literature at large. Project managers invariably take pride in progressing through the stages of the project life-cycle. Indeed, a focus on progress in these terms is arguably central to their sense of selfidentity.

\subsection{Value management as a methodological management style}

Laursen and Svejvig (2016) notably see particular potential in the ideas of Male et al. (2007) who promote value management as a methodological management style. Male and colleagues place much emphasis on their own consultancy experience in the construction sector which they present as a 
combination of action research and grounded theory. In common with the approaches described above, the advocated approach is theoretically ambiguous. Despite the claim to offer a 'methodological' management style there is little attempt to justify the advocated approach in terms of its underlying epistemology. The emphasis of their work is inherently practical. The promoted approach is defined as a style of management characterised by three core elements: (i) making the client's value system (or systems) explicit; (ii) a team-based process which engages stakeholders in participative workshops; (iii) the use of function analysis to promote greater understanding. There is seemingly an assumption that the client's value system (or systems) is essentially pre-existing and can hence in some way be 'revealed'. Paradoxically, there is also a strong focus on exploring multidisciplinary perspectives with a view to identifying a way forward on the basis of consensus and agreement. Yet the continued insistence on function analysis seems to privilege a reliance on a single technique over any broader issues of methodology. Indeed, the classification of function analysis as a 'core element' of value management would seem to sit ill-at-ease with the very idea of a management style. Despite being presented as a 'methodology' the underlying theoretical justification remains tantalisingly elusive. Ultimately, it seems we are asked to accept the advocated approach on the basis that it has an apparent successful track record in practice.

The development of the approach advocated by Male et al. (2007) can be traced back to the publication of Value Management for Design and Construction (Kelly and Male, 1993). Kelly (2007, p. 435) elsewhere describes value management as a 'process that makes explicit and appraises the functional benefits of product, process or service consistent with a value system determined by the client'. Certainly it is easy to understand how such a storyline would seem persuasive to those with an underlying allegiance to technical rationality. Male et al. (2007) allude to the way their supposed methodology has been informed by theoretical perspectives from a range of areas, including business strategy. They further emphasise the need to draw from the broader areas of strategic management, project management and organisational theory. The pluralism on offer would seem to align with that advocated by Söderlund (2011). Yet the areas to which they refer are all theoretically contested and 
it remains unclear which particular strands of thought Male et al. (2007) consider most useful. Perhaps counter-intuitively, it would seem that a degree of theoretical elusiveness may well be a virtue if the aim is to be persuasive to practitioners.

\subsection{Client value systems as preference structures}

Kelly (2007) further eludes to the apparent failure of value management texts to develop the concept of value beyond the three criteria of time, cost and quality or pseudo-formulaic expressions which seek to express value as a relationship between function and cost. Kelly proposes that a 'client value system' can be more fully understood by reference to a recurring set of 'headings', otherwise referred to as 'non-correlated, high order, discretionary performance variables'. The thinking here would seem to align with Söderlund's (2011) 'factor' school of project management which focuses on the factors which supposedly lead to success of failure. Kelly (2007) further describes how the approach was evaluated through a series of nine action research projects. In each case, the client was required to rank the identified variables in order of their perceived importance through a series of pairwise comparisons. The process was notably enacted in the context of a facilitated workshop with the aim of producing a supposedly stable representation of the client's preferences against which options could be assessed. The adopted approach was apparently favoured on the basis of simplicity due to the need for it to be enacted in the context of the obligatory workshop. The practical need for simplicity is of course understandable, but it must also be necessary to satisfy a baseline requirement in terms of rigour. And of course the meaning of rigour would be interpreted differently by different epistemological schools of thought. The more critical observer might also question why the achievement of value is seemingly confined to episodic workshops rather than being a more mainstream concern.

\subsection{Illusions of rationality}

Notwithstanding the above, it is notable that much of the process described by Kelly (2007) would be readily accepted by the advocates of Soft VM. The advocated techniques are not dissimilar to those 
which provide the basis of SMART value management (Green, 1994b). Phillips' (1984) theory of requisite decision modelling provides a compelling explanation of how such techniques can be utilised for the purposes of achieving a 'shared social reality'. By definition, a requisite decision model is developed until the point at which it is considered 'requisite' for the purposes of supporting the decision. It is important to emphasise that the model is not seen to be representative of any sort of external objective reality, but as a means of supporting a negotiated social consensus (or at least an accommodation to which the participants can subscribe). Yet this is not the interpretation offered by Kelly (2007), whose orientation remains focused on revealing a supposed underlying value system which extends beyond the temporal.

Of particular note is Kelly's (2007) expressed discomfort regarding the 'logic errors' which were revealed through the described series of pairwise comparisons. The issue of concern is that of intransitivity, i.e. if a client expresses a preference of $A$ over $B(A>B)$ and $B$ over $C(B>C)$ it then seems illogical for the same client to express a preference for C over A (C>A). Kelly (2007) suggests that this is an issue which needs further research, despite the extensive research on such issues which already exists. Decision scientists famously addressed these apparent shortcomings of rationality back in the 1960s (Tversky, 1969). Conundrums such as these culminated in Tversky and Kahneman's (1981) pioneering work on the way in which rational choice is subject to framing effects.

Despite the above described difficulties, the approach advocated by Male et al. (2007) ostensibly remains plausible in terms of providing a script against which value management might be enacted. Interestingly, the advocated approach would seem to have satisfied the requirements of numerous clients across nine action research projects. Laursen and Svejvig (2016) are therefore not alone in judging the potential of Male et al.'s (2007) approach in terms of the inherent persuasiveness of the narrative on offer. In this respect, an illusion of rationality would seem to be an essential pre-requisite.

\subsection{Metaphors of value management}


Given that current scripts for value management are not precious about issues of epistemology, it is perhaps more enlightening to focus on the organisational metaphors upon which they rely. The idea of gaining insights into the meaning of managerial narratives through the use of metaphors is well established in the literature (cf. Grant and Oswick, 1996; Morgan, 2006). The traditional lexicon of Hard VM undoubtedly leans heavily on machine metaphors in emphasising the importance of efficiency, i.e. the achievement of the required functions at minimum cost. The Hard VM storyline also frequently invokes the psychic prison metaphor as a means of overcoming fixed ways of thinking. The rhetoric is that of optimization, efficiency and cost reduction. In contrast, Soft VM would seem to mobilise a richer array of metaphors with an associated rhetoric of learning, sense making and consensus building. Political metaphors are especially popular among those who promote the need to build consensus among disparate interest groups. Notions of learning (and sense making) are also reliant on cybernetic metaphors. Metaphors can in themselves become traps in that each way of seeing is also a way of not seeing (Morgan, 2006). However - as previously noted - hard and soft approaches are not so easily dichotomised. Expectations of 'metaphorical purity' are unlikely to be realised in practice. Teamwork metaphors transcend both categories, and authors such as Male et al. (2007) offer eclectic approaches that defy simple categorisation. Rather than criticise such sources for their theoretical elusiveness it is perhaps more appropriate to praise them for their rhetorical dexterity. A greater degree of agency must also be accorded to practitioners in mobilising the metaphors which are most appealing to the different audiences which they face at different points in the project life-cycle. Nevertheless, the observation that practitioners and academics rely on metaphors for the purposes of thinking about value creation provides a useful stepping stone towards a narrative perspective.

\section{Towards a narrative perspective}


It is contended that the recurring failure of attempts to reify value require a radically different approach to 'value creation' from those which have prevailed to date. In pointing towards an alternative way forward, attention is given initially to the narrative 'turn' as developed within organisation studies. Thereafter, consideration is directed at the extent to which the co-called 'paradigms' of value management might more meaningfully be re-interpreted as narratives. Of particular note is the way in which such narratives are subject to the isomorphic pressures of institutionalisation. Such a perspective argues against the possibility of practitioners exercising 'free choice' in terms of choosing between different perspectives. However, while institutionalised narratives may well be influential in shaping practice, it is important to recognise they are by no means deterministic. The metaphor of drama is introduced as a means of understanding the relationship between 'theory' in its narrative form and the way in which it is enacted in practice. Finally, in a radical departure from the current espoused research agenda, it is suggested that narratives of value creation might ultimately be best understood as 'identity work'.

\subsection{The 'narrative turn' in organisation studies}

Within the domain of organisation studies, narratives are widely accepted as attempts to impose order and hence to be integral to the process of organising (Currie and Brown, 2003; Weick, 1979). Organisational narratives are invariably characterised by performative intent, they seek to instil a unity of purpose by bringing coherence to disparate experiences (Czarniawska, 2016; Sonenshein, 2010; Vaara et al., 2016). Performative narratives are often repeated in organisations because repetition serves to stabilise particular meanings (Dailey and Browning, 2014). Such narratives are said to become formalised when they are reproduced on corporate websites or published in corporate literature. They further provide the basis for organisational memory by creating shared resources from which employees can draw (Sonenshein, 2010). Published descriptions of value creation could therefore be interpreted as sets of resources from which practitioners can draw rather than as prescriptive methodologies. Narrative theory further recognises that a broad cross-section of 
managers often plays an active part in the construction of narratives through a process of discursive contestation (Ibarra and Barbulescu, 2010). Narratives are therefore seen to be the temporal products of a process of social negotiation which continuously takes place across a series of discursive arenas (Vaara et al., 2016).

The adoption of a narrative approach would hence focus attention on the way in which the meaning of 'value creation' is socially constructed through the use of stories and narratives. Rather than perpetually agonise over issues of definition, it would be accepted that 'value' is a discursive construct subject to multiple interpretations. Published approaches on how value can be realised through projects would also read as quasi-formalised narratives. The narrative of 'Hard VM' can be seen to rely heavily on machine metaphors, and would hence appeal to audiences with a cultural bias towards technical rationality. 'Soft VM' would likewise be accepted as a narrative which draws from different metaphors in order to appeal to audiences with different concerns. The political metaphor would readily appeal to those who recognise the need to negotiate a shared approach with different stakeholders. Male et al.'s (2007) interpretation of value management would in turn be accepted as a narrative which relies on a more eclectic mix of metaphors. Such an interpretation would judge the narratives on the basis of their persuasiveness, rather than on the basis of any supposed theoretical consistency. But it also requires an understanding of the complex processes through which such narratives become formalised, and in some cases institutionalised. Too strong an allegiance to any single metaphorical perspective could well become counter-productive. As Morgan (2006) argues, each way of seeing too easily becomes a way of not seeing.

Given that value is an essential component of the lexicon of modern management, it is reasonable to suggest that narratives advocating how it might best be created are central to contemporary modes of organising. Project-based organisations might equally be expected to be characterised by narratives on how best to derive value from projects. The difficulties of course are multiplied in those case where there are several different agencies whose aspirations need to be satisfied, as is often the case with 
megaprojects (Gil et al., 2017). In these circumstances the formulation and maintenance of a stable narrative of how success should be evaluated is critical. Such managed narratives are likely to be relatively stable in their formalised form, but would nevertheless remain subject to continuous contestation (Dailey and Browning, 2014; Vaara et al., 2016). Senior management would of course see it as part of their role to instil a coherence of purpose across the project organisation - not least in terms of value creation. Narrative repetition would serve to stabilise particular meanings of value, although never quite with sufficient stability to justify description as a 'value system'.

Narratives on the organisational level of course would not be limited to the issue of value, they would typically include elements of corporate vision whilst perhaps also seeking to engender a culture of innovation. The danger with such narratives is that they tend towards the generic, even on occasion tending towards the monotonous. One important means through which managers seek to engage their audience is through the use of stories which relate to their past experience (Boje, 2008; Gabriel, 2000). An important function of senior management is to connect the advocated performative narratives with the lived experiences of the target audience. Such processes are seen to be the very essence of organisations as they are enacted in practice (Boje, 2008; Maclean et al., 2012). The idea that the meaning of value is continuously contested as an integral part of the process of organising chimes with the notion of a 'becoming ontology' as advocated by Tsoukas and Chia (2002) (see also: Linehan and Kavanagh, 2006). This of course is not to deny the essential materiality of capital projects, or indeed the structural components of the landscape within which projects are delivered. But it does accentuate the temporal and ethereal nature of concepts such as 'value', and it does provide a theoretical basis for understanding the way in which the meaning of value is socially constructed, and subject to continuous contestation.

\subsection{Narratives of value management}

From a narrative perspective the current practice of value management can be conceptualised as a series of narrative encounters which take place within the setting of formally convened workshops 
involving the active participation of multiple stakeholders. The reliance on workshops is one of the few points of consistency within the literature, although it would be naïve to suggest that the meaning of 'value' would only ever be contested within the context of workshops. The outcomes from such multi-participant encounters where the meaning of value is contested can further be conceived as negotiated hybrid narratives which provide the basis for short-term decision-making, and indeed the parameters for future discussions regarding the meaning of value. Such a theoretical interpretation moves away from the reification of value towards an understanding of the way in which ascribed meanings are continuously negotiated through the medium of narrative (cf. Brown et al., 2008).

Within project management circles, there would seem to be a degree of dissatisfaction with the currently dominant narrative of value management, not least in terms of its supposed orientation the 'product creation' perspective (cf. Winter et al., 2006). Hence the notion of 'value creation' is advocated as a more progressive alternative. In essence, the very same logic was previously used by Green (1994b) to distinguish value management from the inward-focused narratives of value engineering. It would seem that arguments aimed at rescuing broadly-conceived effectiveness from the pitfalls of narrowly-defined efficiency continue to be persuasive across time and space (cf. Jugdev and Müller, 2005). Value creation may well be a more fashionable term, and if it stimulates a more reflective approach beyond operational efficiency this should certainly be welcomed. But the recent focus on value creation is also indicative of an ongoing attempt to reposition project management as a value-adding discipline. An important part of the narrative is that project managers should take responsibility for value creation rather than leaving it to those who peddle supposedly outdated notions of value management.

Narratives are undoubtedly characterised by particular forms of rhetoric, but they also crucially rely on particular storylines if they are to be persuasive. The traditional narrative of value engineering (aka Hard VM) is characterised by a strong bias in favour of the rhetoric of positivism. The narrative is notable for the way in which it casts the 'value practitioner' in the role of an all-conquering hero who 
is able to cut through the confusion from which others allegedly suffer. The storyline is very much about advocating a systematic approach with a corresponding appeal to the cause of technical rationality. Value practitioners can further be seen to shape the expectations of others through the narratives which they mobilise. Clients who are worried about a cost overspend are likely to be attracted by the narrative of Hard VM. There is therefore a degree of causality between the way value practitioners promote their services and the nature of the work that they secure (Green and Liu, 2007). Practitioners who mobilise a narrative of cost reduction would almost inevitably find themselves involved in retrospective reviews of pre-existing designs with the primary aim of securing cost reduction. The advocates of different versions of value management hence compete in a marketplace of ideas. Different clients are attracted by different storylines, and different storylines may well seem more attractive at different stages of the project.

\subsection{Institutionalised narratives on the sector level}

Notwithstanding the way narratives become formalised on the level of individual organisations, they can also become institutionalised in the form of 'best practice' recommendations on a sectoral level. Examples from the UK construction sector would include the published guidelines produced by ICE (1996) and HM Treasury (1996). Such sources can be seen to provide 'narrative resources' from which practitioners draw. They may also of course choose to pull resources from published textbooks or even (on rare occasions) academic papers. There is therefore a continuous process of hybridisation such that any expectation of methodological purity becomes an entirely unrealistic expectation. Such an interpretation ascribes practitioners with significant agency in combining different narrative resources to meet their own requirements, or to maximise their persuasiveness to a particular targeted client.

Bodies such as the UK-based Institute of Value Management (IVM) noticeably provide web-based resources which are reflective of an eclectic narrative of value management. There is also a Special Interest Group (SIG) on value management within the Association for Project Management (APM). 
Such organisations notably provide the networks from which practitioners can derive legitimacy, and the means of continuously testing provisional narratives against a range of different audiences (cf. Newell et al., 2001). Such processes are thrown into an especially sharp focus when there is a need to produce a formalised narrative for promotional purposes. Such narratives typically provide several metaphorical hooks as a means of attracting interest from as broad a range of clients as possible. From this perspective, vagueness of definition becomes a distinct advantage. Similar arguments have been made within the literature on management fashions (e.g. Abrahamson, 1991; Kieser, 1997). For example, recipes such as business process re-engineering are held to become fashionable due to a combination of rhetorical appeal and definitional elusiveness. This could arguably go some way towards explaining why many formalised narratives of value management are so malleable.

Perhaps the starkest example of the way in which value management becomes institutionalised is provided by the US-based Society of American Value Engineers (SAVE International). Of particular note are the strong expectations that new entrants will adhere to the established 'approved' narrative. Indeed, such expectations are reinforced through the training modules required to become a 'certified value specialist' (CVS). The CVS qualification is important not least because it is a requirement of many US federal agencies. In fairness, the prescribed SAVE methodology has over the years become more catholic in terms of the metaphors from which it draws. Nevertheless, there remains a strong emphasis on function analysis as a means of achieving an acclaimed 'objective perspective'. In contrast, project management organisations such as the Project Management Institute (PMI) and the Association for Project Management (APM) put a greater emphasis on their role as learned societies and are hence more open to disruptive narratives.

None of the above of course should be taken to imply that SAVE certified value specialists are not exemplary in satisfying the expectations of their clients, not least because the expectations of their clients are also shaped by the same dominant narrative. But it is important to emphasise that it cannot be taken for granted that the dominant narrative is in any way deterministic in shaping practice. It 
must also be recognised that practitioners frequently have highly developed skills of improvisation that transcend supposedly theoretical notions of value management 'methodology'.

Institutional pressures leading to isomorphism have also recently been recognised as presenting a challenge to the supposed goal-rationality which lies behind the design of temporary organisations in project-based-organisations (Miterev et al., 2017). We would argue that the dominant narratives of value creation are subject to similar isomorphic pressures within different institutional fields. The allegiance to a common narrative within a particular field can therefore be seen to override notions of rationality as construed by others from outside. Such pressures may account in part for the perennial need to rescue effectiveness from efficiency, for which value creation is but the latest rhetorical vehicle.

\subsection{Value management workshops as acts of drama}

The value management literature notably puts significant emphasis on the use of participative workshops. As observed previously, this is one of very few points of universal agreement. In seeking to escape the constraints of determinism it can be useful to think of these workshops in accordance with the dramaturgical metaphor proposed by Goffman (1959). Engwall and Westling (2004) have previously mobilised the dramaturgical concept in their analysis of the process dynamics of a complex $R \& D$ project. Such a perspective would conceptualise value management workshops as acts of drama which are acted out in accordance with predetermined scripts (albeit with much scope for improvisation). The workshops are hence seen to be enacted with the aim of creating an impression that 'value is being created' thereby satisfying the expectations of the participants (Green and Lui, 2007). The very adoption of the term 'value management' is indicative of an explicit acceptance that 'value' needs to be actively managed (or created). The value management facilitator hence leads the assembled audience in the enactment of an event in accordance with agreed expectations. The explicit purpose of the workshop would typically be framed in the language of value. The favoured narrative would inevitably influence the participants who would be invited to attend. If the event were framed 
in terms of ensuring a shared understanding of the value criteria, this would result in the participation of identified stakeholders from a more strategic level. If, however the event was framed in terms of identifying the potential for cost reduction then it would be more likely that the workshop would be populated by technical experts. In this sense, the performativity of narrative is about more than 'doing things with words', it is about 'bring theory into being' (Gond et al., 2016). Hence value is only given substance through the narratives which are mobilised. There is no 'real value' which lies beyond the various theories of value creation; just as there is no 'real economics' which exists beyond the theory of economics (cf. Callon, 1998). In some respects, a value-specific workshop could be conceived as one narrative encounter amongst many. But the expectations around such workshops are likely to be much higher than those around more routine narrative encounters. Value management workshops would invariably be announced with some degree of fanfare, and they are likely to be more formal in the way they are convened.

The above interpretation is compatible with a broader narrative perspective in that the formalised narratives of value management provide the scripts around which practitioners improvise. In theatrical terminology, there is undoubtedly a tendency for value practitioners to 'ham up' such workshops for the purposes of dramatic effect. In part they are likely to be judged in terms of their performance, but there would also be a strong expectation that such workshops would contribute to a stronger and more coherent narrative for the espoused purposes of value creation.

\subsection{Identity work}

If value has no fixed meaning it is pertinent to ask why it is so dominant in modern organisational narratives, and indeed why value creation has become so important in the context of projects. Part of the answer is that value creation is an aspiration which (almost) everyone can agree with. Whilst there may be endless debates about what value means and how it should be created, there are very few voices arguing that value creation is in itself a bad idea. Hence a convincing narrative of project value creation has the potential to be a strong unifying force in bringing coherence to otherwise disparate 
project participants (cf. Vaara et al., 2016). But narratives can also be interpreted as identity work in that they play an important role in constructing the identity of individual managers and the organisations for whom they work (cf. Brown, 2015). Individual managers can be construed to be continuously striving to create a sense of self-identity which they constantly test against others. This raises an alternative dimension of performativity, one which relates to the role of narrative in creating (and continuously re-creating) a sense of self-identity. Hodgson (2005) has notably applied the concept of performativity to re-interpret the notion of professionalism as constituted within project management.

If a wider perspective is taken which extends beyond the 'product creation' model of project management, it becomes clear that to advocate the importance of value creation is to acknowledge the iconic status of the enterprise culture. To argue that the success of a project should be judged on the basis of value creation is to derive legitimacy from the discourse of the market-based economy. This process of deriving legitimacy from the enterprise culture is especially evident in the way Winter and Szczepanek (2008) draw from Normann's (2001) argument that the crucial competence of business in the $21^{\text {st }}$ Century is that of value creation. To position oneself against value creation therefore risks being seen as old-fashioned and out of touch with modern thinking. Hence many project managers create an identity for themselves as being 'business-savvy' to distance themselves from the (supposed) technocratic project managers of old. To position oneself as a 'creator of value' is equally convincing in the public sector due to the 'internal markets' which are increasingly adopted as a primary means of organising. This of course is not say that project managers adopt such discourses uncritically. Notions of 'social value' are increasingly recognised and project managers may well choose to align themselves which interpretations of value which go beyond the discourse of the enterprise culture. The increasing focus on the importance of external stakeholders to project success is a further important storyline which is often mobilised (Chang et al. 2013; Storvang and Clarke, 2014) Hence the search for value creation may indeed involve a radical re-interpretation of what 'value' means. But the very language in which the debate is conducted is indicative of the iconic status of 
'value' in market-based economies. Hence the need for project managers to project a self-identity on the basis of value creation.

The above argument has been developed on the level of individual, but it can also be extended to the level of organisations offering project management services. In the context of a market-based economy to be seen to be 'adding value' is of central importance in the creation of brand identity. Hence the reason why so many formalised corporate narratives put such strong emphasis on the value of their services. The same argument could also tentatively be applied on the level of the project management profession at large. If project management is to retain legitimacy in the context of the enterprise culture it must be seen to be creating 'value'. Hence the increasing level of interest in value creation in the project management research community. Policy makers can similarly be seen to be involved in 'identity work'. They are constantly creating for themselves - and continuously testing against others - a sense of self-identity.

Notwithstanding the above it is important to emphasise the fluid and temporal nature of identity work (Brown, 2015). It should also be understood that 'value' is just one ingredient in a complex cocktail of storylines around which the self-identities of practitioners are created and continuous contested. For example, the advocates of traditional value engineering (aka Hard VM) strive to create a self-identity for themselves as straight-talking, tough 'trouble-shooters' who are capable of disrupting pre-existing patterns of complacency. These are the images they consistently draw upon in their storytelling by which means they project their self-identity to others. In contrast, the advocates of Soft VM strive to create a very different reality for themselves, based on a very different self-identity. Their language is much less confrontational, and much more collaborative. Rather than creating a self-identity as trouble-shooters, they are more concerned with creating a self-identity as helpers and empathetic listeners. Through the stories they tell they consistently cast themselves in the role of facilitators who work in participation with others to achieve consensus amongst disparate interest groups. Similar arguments could easily be made for the different modes of project management. Precisely what role 
the advocates of the emerging narrative of 'value creation' foresee for themselves would be a worthwhile empirical study, best conducted through narrative interviews (Hollway and Jefferson, 2005; Mishler, 1991).

\section{Conclusions}

\subsection{Value as a socially constructed narrative}

This conceptual paper has argued that value is in essence a social construct, and that the processes of social construction are rooted in language. It is on this basis that we contend that value creation in projects is a process which lends itself to interpretation from a narrative perspective. It was stated from the outset that the arguments should be judged on the basis of their explanatory power, and it is around this theme that the conclusions are presented. It is important initially to emphasise that there is nothing in this paper which denies the materiality of projects and the structural landscape within which they are delivered.

The shift towards understanding value as a socially constructed narrative is liberating in a number of important respects. Firstly, it eliminates any expectation that the way in which practitioners describe value creation is in any way representative of a supposed set of deeply-held assumptions. Hence it becomes misconceived to attempt to pigeon-hole practitioners in accordance with preconceived paradigmatic frameworks. Yet the storylines mobilised by practitioners can be accessed empirically and hence lend themselves to analysis from a narrative perspective. This would apply equally to supposed dichotomies such as Hard VM vs Soft VM and to previous paradigmatic typologies such as that developed by Burrell and Morgan (1979). It would also apply to the six-facet ontological framework for project management research suggested by Gauthier and Ika (2012). We are relatively comfortable with such frameworks as a basis for stimulating discussion about research, but we would question their usefulness as lenses for the purposes of classifying practice. 
The shift towards understanding value management from a narrative perspective also provides a basis for explaining the complex processes of hybridisation which occur across multiple discursive arenas. Such processes of hybridisation not only take place across (and between) organisations, but also over time. Particular narratives may well be originally advocated as coherent theoretical positions, but the sanctity of any notion of methodology is unlikely to survive the multi-participant contestation of even the very first discursive arena. There is an obvious parallel here with the well-known military adage that 'no plan survives contact with the enemy'.

\subsection{Points of contention}

Notwithstanding the above, it is recognised that the claim that value is a social construct is likely to be contentious amongst those whose view of project management is framed by notions of technical rationality. It is hence important to emphasise that scholars have searched for objective definitions of value for centuries. The sustained lack of progress is surely suggestive of the need for an alternative theoretical perspective. Realist assumptions regarding the 'factors' which contribute to value have consistently been found to be sadly deficient. If value cannot meaningfully be defined in terms of identifiable objective characteristics, then it clearly cannot be 'optimised'. Simon's $(1955,1956)$ notion of bounded rationality remains of critical importance, likewise the seminal contributions of Tversky and Kahneman (1981). Hence realist notions of value maximisation must forever remain a pipedream. And yet the rhetoric of value maximisation remains hugely persuasive among practising project managers and also in formalised policy narratives. The simple reality is that the narrative perspective offers explanations which have consistently escaped the explanatory powers of the realist perspective.

We would however be cautious of aligning ourselves with any supposed grouping such as the 'proponents of postmodernity'. Gauthier and lka (2012) suggest that postmodernists are committed to demonstrating that 'reason and knowledge are only narratives and means of domination'. There are no doubt some advocates of 'postmodernity' to whom this generalisation might apply, but we 
would hope that the arguments presented in this paper are evaluated on their own merits. Postmodernism is a slippery term which is not so easily defined. We would however take issue with the word 'only' which rather serves to trivialise the idea of narrative from the outset. We would further argue that reason and knowledge are often entirely inseparable from the narrative form. History is an obvious example - unless of course history is reduced to a series of undisputed factual events arranged along a timeline. We would also contest the suggestion that the advocates of 'postmodernity' are primarily concerned with exposing reason and knowledge as a means of domination. The perspective developed in the current paper argues that narratives are anything but deterministic. It has also been argued that narratives have to be credible if they are to be persuasive, hence they have to relate to the lived experiences of those at whom they are directed. The threshold for credibility in terms of reason and knowledge is hence in practice often very high. Such an argument is central to the notion of a requisite decision model, whereby the model needs to meet the standards of sophistication as applied by the participants (Phillips, 1984).

\subsection{Formalised narratives of value and informal stories of 'values'}

Existing approaches to value creation have been found to struggle in terms of the adopted unit of analysis, with a tendency to blur between 'client value' on the level of organisations and 'values' in the sense of the 'deeply-held beliefs' of individuals (Thomson et al., 2003; Thyssen et al., 2010). The adopted narrative approach however resolves this conundrum by focusing on the processes of continuous discursive contestation. Of particular importance is the interaction between formalised narratives and the personalised stories mobilised by individuals. Given that 'deeply-held beliefs' cannot meaningfully be accessed through simplistic questionnaires, we would argue that they can best be understood in the temporal terms in which they are expressed, i.e. the stories contributed by individuals in the context of narrative encounters (including those billed as value management workshops). We would also see such stories to be closely intertwined with issues of identity work. Indeed, we would tend to see personal values as inherently inseparable from identity work. Hence 
individual stories would continuously be tested against a series of different audiences as particular self-identities are created and contested. If the stories mobilised were found to be sufficiently persuasive, they would over time impact upon and perhaps shape the more formalised organisational narratives of value. It is true of course that senior managers would have greater credibility in terms of their ability to shape corporate narratives of value, but we would not see anything especially sinister in such an observation. This is what senior managers in organisations are expected to do; they are expected to provide others with a sense of direction. The explanatory power of the narrative perspective is such that the traps of determinism are avoided; all such narratives remain contestable and their relationship with practice remains heavily mediated.

The above interpretation also avoids the previously unsurmountable problem of trying to predict the needs of future stakeholders yet to be identified. Formalised narratives of value can be seen to outlive the original interest groups who generated them, and indeed can be seen to continue to morph throughout the extended project life-cycle. In a sense such narratives can be equated with the concept of a 'client value system', with the proviso of course that they are subject to continuous contestation. It is worth emphasising again that narratives are in no way dependent upon the continued involvement of the individual stakeholders identified at project conception. But it must also be recognised that projects require decisions to be made - often with direct material consequences. Such decisions need to be accountable with the explicit support of key stakeholders. This of course does not mean that any consensus will survive over time. Project success is always likely to fall victim to shifting aspirations. It must also be recognised that narratives may well serve to shape materiality, but also that materiality will serve to shape future narratives.

\subsection{Recommendations for future research}

There is of course a need to support the developed theoretical perspective through empirical research. The required research object is that of the narratives of value creation which are developed in practice. There is a need to chart the ways in which formalised narratives of value are re-shaped 
over time through the micro-interactions with the anecdotal stories derived from the personal experiences of individuals (cf. Musca et al., 2014) There is also a need for research which sheds light on how project managers (and others) mobilise resources derived from formalised narratives of value creation. There is an especially important need for research which focuses on identity work in project contexts, and the ways in which the self-identities of project managers are changing. But perhaps of most importance is the need to avoid replicating the research agendas of the past, especially in terms of the reification of value. In truth, with few notable exceptions (e.g. Havermans et al., 2015), the potential of narrative methods remains almost relatively unexplored.

\section{References}

Artto, K., Ahola, T., Vartiainen, V., 2016. From front end of projects to the back end of operations: Managing projects for value creation throughout the system lifecycle. International Journal of Project Management, 34(2), 258-270.

Abrahamson, E., 1991. Management fads and fashions: The diffusion and rejection of innovations. Academy of Management Review, 16(3), 586-612.

Ackoff, R.L., 1987. OR, a post mortem. Operations Research, 35(3), 471-474.

Ahola, T., Laitinen, E., Kujala, J., Wikström, K., 2008. Purchasing strategies and value creation in industrial turnkey projects. International Journal of Project Management, 26(1), 87-94.

Amtoft, M., 1994. Storytelling as a support tool for project managers. International Journal of Project Management, 12(4), 230-233.

Association for Project Management (APM), 2018. Value and Benefits. Association for Project Management, Princes Risborough, UK.

Atkinson, R., 1999. Project management: Cost, time and quality, two best guesses and a phenomenon, it's time to accept other success criteria. International Journal of Project Management, 17(6), 337-342. 
Boddy, D., Paton, R., 2004. Responding to competing narratives: lessons for project managers. International Journal of Project Management, 22(3), 225-233.

Boje, D.M., 2008. Storytelling Organizations. Sage Publications, London, UK.

Boje, D.M., Oswick, C., Ford, J.D., 2004. Language and organization: The doing discourse. Academy of Management Review, 29(4), 571-577.

Brown, A.D., Stacey, P., Nandhakumar, J., 2008. Making sense of sensemaking narratives. Human Relations, 61(8), 1035-1062.

Brown, A.D. 2015. Identities and identity work in organizations. International Journal of Management Reviews, 17(1), 20-40.

Burrell, G., Morgan, G., 1979. Sociological Paradigms and Organisational Analysis. Gower, Aldershot, UK.

Callon, M., 1998. The Law of the Markets. Blackwell, Oxford, UK.

Chang, A., Chih, Y.-Y., Chew, E., Pisarski, A., 2013. Reconceptualising mega project success in Australian defence: Recognising the importance of value co-creation. International Journal of Project Management, 31(8), 1139-1153.

Checkland, P.B., 1981. Systems Thinking, Systems Practice. Wiley, Chichester, UK.

Checkland, P.B., Scholes, J., 1991. Soft System Methodology in Action. Wiley, Chichester, UK.

Checkland, P.B., 2001. Soft systems methodology, in J., Rosenhead, J., Mingers, J. Rational Analysis for a Problematic World Revisited, (Eds.). Wiley, Chichester, UK, pp 61-89.

Cicmil, S., Hodgson, D., 2006. Making projects critical: An introduction. In D. Hodgson, S. Cicmil, Making Projects Critical, Palgrave, Basingstoke, pp 1-25.

Cleland, D. I., Ireland, L., 2002. Project Management: Strategic Design and Implementation. McGrawHill, New York.

Crawford, L.H., Costello, K., Pollack, J., Bentley, L., 2003. Managing soft change projects in the public sector. International Journal of Project Management, 21(6), 443-448. 
Currie, G., Brown, A.D., 2003. A narratological approach to understanding processes of organizing in a UK hospital. Human Relations, 56(5), 563-586.

Czarniawska, B., 2016. Performativity of social sciences as seen by organization scholar. European Management Journal, 34(4), 315-318.

Dailey, S.L., Browning, L., 2014. Retelling stories in organisations: understanding the functions of narrative repetition. Academy of Management Review, 39(1), 22-43.

Dell'Isola, A., 1982. Value engineering in the construction industry (Ed.). Van Nostrand Reinhold, NY.

Ellis, R.C.T., Wood, G.D., Keel, D.A., 2005. Value management practices of leading UK cost consultants. Construction Management and Economics, 23(5), 483-493.

Engwall, M., Westling, G., 2004. Peripety in an R\&D drama: capturing a turnaround in project dynamics. Organization Studies, 25(9), 1557-1578.

Friend, J., Hickling, A., 1987. Planning under Pressure: The Strategic Choice Approach. Pergamon, Oxford, UK.

Gabriel, Y., 2000. Storytelling in Organizations: Facts, Fictions, and Fantasies. Oxford: Oxford University Press.

Garfinkel, H., 1967. Studies in Ethnomethodologies. Prentice Hall, NJ.

Gauthier, J-B., Ika, L.A., 2012. Foundations of project management research: an explicit and six-facet ontological framework. Project Management Journal, 43(5), 5-23.

Gil, N., 2010. Language as a resource in project management: a case study and a conceptual framework. IEEE Transactions on Engineering Management, 57(3), 450-462.

Gil, N., Lundrigan, C., Pinto, J.K., Puranam, P., 2017. Megaproject Organization and Performance: The Myth and Political Reality. Project Management Institute, Pennsylvania, USA.

Gillier, T., Hooge, S., Piat, G., 2015. Framing value management for creative projects: an expansive perspective. International Journal of Project Management, 33(4), 947-960.

Goffman, E., 1959. The Presentation of Self in Everyday Life. Doubleday, NY. 
Gond, J.-P., Cabantous, L., Harding, N., Learmonth, M. 2016. What do we mean by performativity in organizational and management theory? The uses and abuses of performativity. International Journal of Management Reviews, 18(4), 440-463.

Grant, D., Oswick, C., 1996. Metaphor and Organizations. Sage, London, UK.

Green, S.D., 1994a. A paradigm crisis in value management? in Proc. 10th Annual ARCOM Conference, Loughborough University of Technology, (eds. R. M. Skitmore and Betts, M.), Vol. 2, pp 410-421.

Green, S.D., 1994b. Beyond value engineering: SMART value management for building projects. International Journal of Project Management, 12(1), pp 49-56.

Green, S.D., 1999. A participative research strategy for propagating soft methodologies in value management practice. Construction Management and Economics, 17(3), pp 329-340.

Green, S.D., Lui, A.M.M., 2007. Theory and practice in value management: a reply to Ellis et al (2005). Construction Management and Economics, 25(6), 649-659.

Havermans, L. A., Keegan, A., Den Hartog, D.N., 2015. Choosing your words carefully: Leaders' narratives of complex emergent problem resolution. International Journal of Project Management, 33(5), 973-984.

Hodgson, D., 2005. 'Putting on a professional performance': performativity, subversion and project management. Organization, 12(1), 51-68.

Hodgson, D., Cicmil, S., 2006. Making Projects Critical, Palgrave, Basingstoke.

Hollway, W., Jefferson, T., 2005. Doing qualitative interviews differently: Free association, narrative and the interview method. Sage Publications., London, UK.

HM Treasury, 1996. CUP Guidance note No54: Value Management. HM Treasury, London, UK.

Ibarra, H., Barbulescu, R., 2010. Identity as narrative: Prevalence, effectiveness and consequences of narrative identity work in macro work role transition. Academy of Management Review, 35(1), 135-154. 
Ika, L. A., 2009. Project success as a topic in project management journals. Project Management Journal, 40(4), 6-19.

Institution of Civil Engineers (ICE), 1996. Creating Value in Engineering. Thomas Telford, London, UK. Institution of Civil Engineers (ICE), 2017. From Transaction to Enterprise: A New Approach to Delivering High Performing Infrastructure. Institution of Civil Engineers, London, UK.

Jugdev, K., Müller, R., 2005 A retrospective look at our evolving understanding of project success. Project Management Journal, 36(4), 19-31.

Kieser, A., 1997. Rhetoric and myth in management fashion. Organization, 4(1), 49-74.

Kelly, J., 2007. Making client values explicit in value management workshops. Construction Economics and Management, 25(4), 435-442.

Kelly, J., Male, S., 1993. Value Management in Design and Construction: The Economic Management of Projects. Spon, London, UK.

Keys, P., 1984. Traditional management science and the emerging critique, in: M.C. Jackson, P. Keys, (Eds.), New Directions in Management Science. Gower, Aldershot, pp. 1-5.

Kreiner, K. 2004. Restoring Project Success as Phenomenon, in R. A. Lundin, \& M. Hällgren (Eds.), Advancing Research on Projects and Temporary Organizations (19-38). Frederiksberg: Copenhagen Business School Press.

Laursen, M., Svejvig, P., 2016. Taking stock of project value creation: a structured literature review with future directions for research and practice. International Journal of Project Management, 34(4), 736-747.

Lepak, D.P., Smith, K.G., Taylor, M.S., 2007. Value creation and value capture: A multi-level perspective. Academy of Management Review, 32(1), 180-194.

Linehan, C., Kavanagh, D., 2006. From project ontologies to communities of virtue, in D. Hodgson, S. Cicmil (Eds.), Making Project Critical, Palgrave MacMillan, Basingstoke, UK, pp 51-67.

Maclean, M., Harvey, C., Chia, R., 2012. Sensemaking, storytelling and the legitimization of elite business careers. Human Relations, 65(1), 17-40. 
Male, S., Kelly, J., Gronqvist, M., Graham, D., 2007. Managing value as a management style for projects. International Journal of Project Management, 25(2), 107-114.

Martinsuo, M., Killen, C.P., 2014. Value management in project portfolios: identifying and assessing strategic value. Project Management Journal, 45(5), 56-70.

Mingers, J., 1980. Towards an appropriate social theory for applied systems thinking: critical theory and Soft Systems Methodology. Journal of Applied Systems Analysis, 7(1), 41-50.

Mingers, J. 2004. Paradigm wars: ceasefire announced who will set up the new administration? Journal of Information Technology, 19(3), 165-171.

Mingers, J., Gill A., 1997. Multimethodology (eds.). Wiley, Chichester, UK.

Mishler, E.G., 1991. Research Interviewing: Context and Narrative. Harvard University Press, Harvard, USA.

Miterev, M., Engwall, M., Jerbrant, A., 2017. Mechanisms of isomorphism in project-based organizations. Project Management Journal, 48(5), 9-24.

Morgan, G., 2006. Images of Organisation. Sage, London, UK.

Morris, P.W.G., 1994. The Management of Projects. Telford, London, UK.

Morris, P. W.G., 2013. Reconstructing Project Management. Wiley-Blackwell, London, UK.

Musca, G.N., Mellet, C., Simoni, G., Sitri, F., de Vogüé, S., 2014. “Drop your boat!”: the discursive coconstruction of project renewal: The case of the Darwin mountaineering expedition in Patagonia. International. Journal of Project Management, 32(7), 1157-1169.

Newell, S., Robertson, M., Swan, J., 1998. Professional associations as 'brokers', facilitating networking and the diffusion of new ideas: advantages and disadvantages. In: Alvarez, J.L. (eds.) The Diffusion and Consumption of Business Knowledge. Macmillan, London, UK, pp. $182-200$.

Normann, R., 2001. Reframing Business: When the Map Changes the Landscape. Wiley, London, UK. Paauwe, J., Boselie, B., 2006. Changing 'strategic HRM' and the relevance of the institutional setting. Human Resource Management Journal, 13(3), 56-70. 
Pinto, J. K., Stevin, D. P., 1988. Critical success factors across the project life cycle. Project Management Journal, 19(3), 67-75.

Pirsig, R.M., 1974. Zen and the Art of Motorcycle Maintenance: An inquiry into Value. HarperCollins Publishers, NY.

Phillips, L.D., 1984. A theory of requisite decision models. Acta Psychologica, 56(1-3), 29-48.

Rhodes, C., Brown, A.D., 2005. Narrative, organizations and research. International Journal of Management Reviews, 7(3), 167-188.

Rosenhead, J., Mingers, J., 2001. Rational Analysis for a Problematic World Revisited (Eds.). Wiley, Chichester, UK.

Serra, C.E.M., Kunc, M., 2015. Benefits realisation and its influence on project success and the execution of business strategies. International Journal of Project Management, 33(1), 53-66.

Simon, H.A., 1955. A behavioral model of rational choice. Quarterly Journal of Economics, 69(1), 99118.

Simon, H A. 1956. Rational choice and the structure of the environment. Psychological Review, 63, $129-38$.

Smyth, H.J., Morris, P.W.G., 2007. An epistemological evaluation of research into projects and their management: methodological issues. International Journal of Project Management, 25(4), 423-436.

Söderlund, J., 2004. Building theories of project management: past research, questions for the future. International Journal of Project Management, 22(3), 183-191.

Söderlund, J., 2011. Pluralism in project management: navigating the crossroads of specialization and fragmentation. International Journal of Management Reviews, 13(2), 153-176.

Sonenshein, S., 2010. We're changing - or are we? Untangling the role of progressive, regressive, and stability narratives during strategic change implementation. Academy of Management Journal, 53(3), 477-512. 
Stingl, V., Geraldi, J., 2017. Errors, lies and misunderstandings: systematic review on behavioural decision making, International Journal of Project Management, 35(2), 121-135.

Stone, P.A., 1966. Building Economy: Design, Production, and Organisation: A Synoptic View. Pergamon Press, Oxford, UK.

Storvang, P., Clarke, A.H., 2014. How to create a space for stakeholders' involvement in construction. Construction Management and Economics, 32(12), 1166-1182.

Thiry, M., 2001. Sensemaking in value management. International Journal of Project Management, 19(2), 71-77.

Thiry, M., 2002. Combining value and project management into an effective programme management model. International Journal of Project Management, 20(3), 221-227.

Thomson, D. S., Austin, S. Devine-Wright, H., Mills, G., 2003. Managing value and quality in design. Building Research \& Information, 31(5), 334-345.

Thyssen, M.H., Emmitt, S., Bonke, S., Kirk-Christoffersen, A., 2010. Facilitating client value creation in the conceptual design phase of construction projects: a workshop approach, Architectural Engineering and Design Management, 6(1), 18-30.

Tsoukas, H., 1994. Refining common sense: Types of knowledge in management studies, Journal of Management Studies, 31(6), 761-780.

Tsoukas, H., Chia, R., 2002. On organizational becoming: Rethinking organizational change. Organization Science, 13(5), 567-582.

Tversky, A., 1969. Intransitivity of preferences. Psychological Review, 76(1), 31-48.

Tversky, A., Kaneman, D., 1981. The framing of decisions and the psychology of choice. Science, 211(4481), 453-458.

Vaara, E., Sonenshein, S., Boje, D., 2016. Sources of stability and change in organizations: Approaches and directions for future research. The Academy of Management Annals, 10(1), 495-560.

Weick, K.K., 1979. The Social Psychology of Organizing. Addison-Wesley, Reading, MA. 
Winch, G.M., 2013. Escalation in major projects: Lessons from the Channel Fixed Link. International Journal of Project Management, 31(5), 724-724.

Winter, M., Smith, C., Morris, P., Cicmil, S., 2006. Directions for future research in project management: The main findings of a UK government-funded research network. International Journal of Project Management, 24(8), 638-649.

Winter, M., Szczepanek, T., 2008. Projects and programmes as value creation processes: A new perspective and some practical implications. International Journal of Project Management, 26(1), 95-103.

Yeo, K.T., 1993. System thinking and project management - time to reunite. International Journal of Project Management, 11(2), 111-117.

Zwikael, O., Smyrk, J., 2012. A general framework for gauging the performance of initiatives to enhance organizational value. British Journal of Management, 23(1), S6-S22. 